\title{
Curative-intent pancreas resection for pancreatic metastases: surgical and oncological results
}

\author{
Sophia Chikhladze ${ }^{1} \cdot$ Ann-Kathrin Lederer ${ }^{1,2}$. Christian M. Kühlbrey ${ }^{1}$. Julian Hipp ${ }^{1}$ Olivia Sick ${ }^{1}$. \\ Stefan Fichtner-Feigl ${ }^{1}$. Uwe A. Wittel ${ }^{1}$
}

Received: 12 August 2019 / Accepted: 18 February 2020 / Published online: 24 February 2020

(c) The Author(s) 2020

\begin{abstract}
Background Pancreatic metastasis is a rare cause for pancreas surgery and often a sign of advanced disease no chance of curative-intent treatment. However, surgery for metastasis might be a promising approach to improve patients' survival. The aim of this study was to analyze the surgical and oncological outcome after pancreatic resection of pancreatic metastasis. Methods This is a retrospective cohort analysis of a prospectively-managed database of patients undergoing pancreatic resection at the University of Freiburg Pancreatic Center from 2005 to 2017.

Results In total, 29 of 1297 (2\%) patients underwent pancreatic resection due to pancreatic metastasis. 20 (69\%) patients showed metastasis of renal cell carcinoma (mRCC), followed by metastasis of melanoma $(n=5,17 \%)$, colon cancer $(n=2$, $7 \%)$, ovarian cancer $(\mathrm{n}=1,3 \%)$ and neuroendocrine tumor of small intestine $(\mathrm{n}=1,3 \%)$. Two (7\%) patients died perioperatively. Median follow-up was 76.4 (range 21-132) months. 5-year and overall survival rates were $82 \%$ (mRCC $89 \%$ vs. non-mRCC 67\%) and 70\% (mRCC 78\% vs. non-mRCC 57\%), respectively. Patients with mRCC had shorter disease-free survival (14 vs. 22 months) than patients with other primary tumor entities.

Conclusion Despite malignant disease, overall survival of patients after metastasectomy for pancreatic metastasis is acceptable. Better survival appears to be associated with the primary tumor entity. Further research should focus on molecular markers to elucidate the mechanisms of pancreatic metastasis to choose the suitable therapeutic approach for the individual patient.
\end{abstract}

Keywords Pancreas surgery $\cdot$ Renal cell carcinoma $\cdot$ Melanoma $\cdot$ Survival $\cdot$ Metastasectomy

Sophia Chikhladze

sophia.chikhladze@uniklinik-freiburg.de

Ann-Kathrin Lederer

ann-kathrin.lederer@uniklinik-freiburg.de

Olivia Sick

olivia.sick@uniklinik-freiburg.de

Stefan Fichtner-Feigl

stefan.fichtner@uniklinik-freiburg.de

Uwe A. Wittel

uwe.wittel@uniklinik-freiburg.de

1 Department of General and Visceral Surgery, Medical Center - University of Freiburg, Faculty of Medicine, University of Freiburg, Hugstetter Straße 55, 79106 Freiburg im Breisgau, Germany

2 Center for Complementary Medicine, Department of Environmental Health Sciences and Hospital Infection Control, Medical Center - University of Freiburg, Faculty of Medicine, University of Freiburg, Breisacher Straße 115b, 79106 Freiburg im Breisgau, Germany

\section{Abbreviations \\ mRCC Metastatic renal cell carcinoma/cancer \\ mnRCC Metastatic other tumor identities \\ POPF Postoperative pancreatic fistula}

\section{Introduction}

Pancreatic metastasis from other primary malignancies is a rare cause for pancreas surgery. Isolated pancreatic metastasis is known to occur in cases of renal and colorectal carcinoma, melanoma, breast and lung cancer [1]. The rate of metastasis to the pancreas is about $2 \%$ of all pancreatic malignancies [2-4]. Autopsy records of patients with malignant diseases excluding primary pancreatic cancer revealed that $15 \%$ had pancreatic metastasis and, thus, more frequently than clinically diagnosed [5]. It can be assumed that patients with pancreatic metastases are often in an advanced stage of primary disease, and the diagnosis 
of pancreatic metastasis is an incidental finding as part of follow-up care. Most of these patients present no metastasis-related symptoms $[6,7]$. Curative intent of surgery is only given in patients with controlled primary malignant disease, which leads to a small fraction of patients undergoing pancreas resection. The most common primary entity with isolated pancreatic metastasis is renal cell carcinoma (mRCC) showing pancreatic metastasis usually years after diagnosis of the primary tumor $[1,8-10]$. Resection of pancreatic metastasis of mRCC was associated with improved patient survival compared to metastasis resection of other primary tumors $[1,8,11,12]$. Due to the rarity of resectable pancreatic metastases, no guideline has been established for surgical treatment of different tumor entities. Only few data of surgical and oncological treatment have been reported to date from case reports or small sample size studies. The potential advantage and also the risk of pancreatic resection for these patients still remain unclear. The objective of this study was to analyze the surgical and oncological outcome after pancreatic resection of pancreatic metastasis and, therefore, we retrospectively evaluated our own prospectivelycollected institutional data of patients who underwent pancreatic resection.

\section{Methods}

Data were retrospectively obtained from the pancreatic surgery database of the University of Freiburg Medical Center, which contains prospectively-collected data for all pancreatic resections performed at our institution. Inclusion criterion was histologically-proven pancreatic metastasis. All kinds of primary tumor entities except primary pancreas carcinoma were eligible for inclusion. Patients with tumor infiltration in the pancreas due to cavitary metastasis were not included. All kinds of surgical approaches were considered. Primary outcome was overall survival of mRCC patients compared to patients with other metastatic tumor entities (nmRCC). Patients' demographic data including sex, age, comorbidities, time between surgery of primary tumor and pancreatic metastasis, localization of metastasis and extent of tumor, imaging modalities used, kind/extent of surgery, interventions, histology, complications and clinical and oncological outcome were analyzed. Perioperative complications were graded according to the recommendations of the International Study Group of Pancreatic Surgery (ISGPS) criteria [13-15] and the Clavien-Dindo classification $[16,17]$. Perioperative mortality was defined as death during the initial hospitalization or within 30 days of the operative date.

Study size depended on feasibility, as pancreatic metastases are rare. Data are presented as median values and their ranges unless otherwise specified. Continuous variables were analyzed using the Mann-Whitney-U test and categorical variables were analyzed using the Chi-squared test or Fisher exact test, as appropriate. Survival analysis was performed using the Kaplan-Meier method. A p value of $<0.05$ was considered statistically significant. All statistical analyses were performed with SPSS for Windows (version 25.0, SPSS Inc., Chicago, IL, USA). The study was approved by the Ethics Committee of the University of Freiburg Medical Center.

\section{Results}

We retrospectively analyzed data of 1297 patients undergoing pancreatic resection between $01 / 2005$ and $12 / 2017$. Only $2 \%$ of those $(n=29)$ underwent pancreatectomy for pancreatic metastatic disease. All patients were operated with curative intent. The median age of all patients was 66 years (range 44-79). More than half of the patients $(n=16,55 \%)$ were male. In two-thirds of the patients $(n=19,66 \%)$ pancreatic metastasis was diagnosed as a part of follow-up care. Only 10 of 29 patients (34\%) had clinical symptoms, which were mostly unspecific $(n=8,28 \%)$. Two patients (7\%) showed tumor-related symptoms: One patient (3\%) presented with jaundice and another with delayed gastric emptying. The diagnostics of pancreatic lesions included CT-scan in 18 (62\%), MRI in $13(45 \%)$, both CT and MRI in $6(21 \%)$ patients and PET-CT in $14(48 \%)$. Since the primary diagnosis was known to the radiologist, sensitivity of imaging could not be definitively assessed. Sensitivity of CT, MRI and PET-CT was $89 \%, 92 \%$ and $71 \%$, respectively. Seventeen patients (59\%) showed single metastasis and 12 patients (41\%) had on average 3 (range 2-15) metastases in the pancreas. At the time of surgery, 13 patients $(45 \%)$ had extra-pancreatic metastasis for which curative-intent resection was also planned. $19(65 \%)$ of the patients had a previous history of metastases, and $18(62 \%)$ patients had had on average one resection of metastases (range 0-8 metastatic resections) before resection for pancreatic metastases. Metastases were metachronous in $97 \%$ of the patients $(n=28)$. The majority of metastases were located in the pancreatic tail $(n=8,28 \%)$, followed by the head $(n=6,21 \%)$ and body $(n=6,21 \%)$. Nine patients $(31 \%)$ had lesions in several localization in pancreas. The majority of pancreatic metastases originated from renal cell carcinoma $(n=20$, $69 \%)$, mostly from the left kidney $(n=11,55 \%)$. Other primary tumor entities were melanoma $(n=5,17 \%)$, colon cancer $(n=2,7 \%)$, ovarian cancer $(n=1,3 \%)$ and NET of the small intestine $(\mathrm{n}=1,3 \%)$. The median tumor size was $21 \mathrm{~mm}$ (range 4-60). Seventeen patients (59\%) underwent distal pancreatectomy, pancreatic head resection was performed in $6(21 \%)$ and total pancreatectomy in $6(21 \%)$ patients. Splenectomy was performed in 18 patients $(62 \%)$ 
and adrenalectomy in three patients (10\%). One patient each (3\%) underwent liver or gastric resection and further two (6\%) underwent small bowel resection. Three patients (10\%) underwent laparoscopic pancreas surgery (1 total pancreatectomy and 2 distal pancreatectomies). R0-resection was possible in 25 patients (86\%). Median operative time was 281 min (range 154-556). Perioperative blood transfusion was needed in 4 patients (14\%). Overall, 21 patients (72\%) suffered from postoperative complications. Complications requiring intervention (Clavien-Dindo III-V) were observed in 9 patients (31\%) of whom 4 developed organ dysfunction. Clinically-relevant grade $\mathrm{B}$ and $\mathrm{C}$ pancreatic fistula occurred in 14 patients (61\%). Two patients (7\%) died during the postoperative course due to liver failure and multi-organ failure due to gastric perforation. The median follow-up time of all patients was 76.4 (range 21-132) months. Overall survival rate was $70 \%(n=19) .5$-year survival was $82 \%(n=22)$.

\section{Renal cell carcinoma vs. other tumor entities}

Patients were divided into two groups for further analysis: Metastatic renal cell cancer (mRCC) and metastases due to other tumor entities (mNRCC). Patients with $\mathrm{mRCC}$ were significantly older $(\mathrm{p}=0.02)$ and, due to past renal resection, more frequently had renal-dependent diseases such as hypertension $(\mathrm{p}=0.02)$ and renal insufficiency $(\mathrm{p}=0.002)$. ASA score was slightly but non-significantly higher in patients with mRCC. BMI, heart and pulmonary comorbidities and diabetes were similar in both groups (Table 1). Before pancreas surgery, patients with mRCC had no other therapy (radiation, chemotherapy or targeted therapy) than surgery and RFA, whereas patients with nmRCC had several other therapies [surgery in 8 cases $(89 \%)$, chemotherapy in 3 cases (33\%), radiation in 3 cases $(33 \%)$ and interferon therapy in 5 cases (56\%)]. Diagnostic methods differed significantly between the groups (Table $2, p=0.014$ ). Localization of pancreatic metastases was similar in both groups with the exception of multiple metastases, which were only found in mRCC patients $(n=9$, Table 2$)$. The median time between resection of primary tumor and pancreatic metastasis was 116 months (range 6-331 months) for mRCC and 66 months (range 13-108 months) for other tumor entities $(\mathrm{p}=0.07)$. Perioperative blood transfusion was only needed in patients with mRCC. Development of postoperative complications was similar in both groups (mRCC 70\% vs. nmRCC 78\%, Table 3). Clinically-relevant postoperative pancreatic fistula (POPF grade B and C) occurred in 9 (64\%) mRCC patients and in $5(55 \%)$ mnRCC patients (rate excludes patients with total pancreatectomy). Patients with mRCC stayed slightly but non-significantly longer in the intensive care unit and in
Table 1 Demographic data, comorbidities and survival

\begin{tabular}{|c|c|c|c|c|}
\hline Parameter & All $(n=29)$ & $\operatorname{mRCC}(\mathrm{n}=20)$ & $\operatorname{mnRCC}(\mathrm{n}=9)$ & $\mathrm{p}$ \\
\hline \multirow[t]{2}{*}{$\operatorname{Sex}[\mathrm{n}(\%)]$} & 이 $13(45 \%)$ & 이 $10(50 \%)$ & ○3 $(33 \%)$ & NS \\
\hline & ठ16(55\%) & ○10 (50\%) & $6(67 \%)$ & \\
\hline Age [years, median (range)] & $66(44-79)$ & $68(53-78)$ & $63(45-74)$ & 0.02 \\
\hline ASA-Score $[\mathrm{n}(\%)]$ & & & & NS \\
\hline I & $0(0 \%)$ & $0(0 \%)$ & $0(0 \%)$ & \\
\hline II & $17(59 \%)$ & $10(50 \%)$ & $7(78 \%)$ & \\
\hline III & $11(38 \%)$ & $9(45 \%)$ & $2(22 \%)$ & \\
\hline IV & $1(3 \%)$ & $1(5 \%)$ & 0 & \\
\hline BMI $\left[\mathrm{kg} / \mathrm{m}^{2}\right.$, median (range) $]$ & $28(20-41)$ & $29(20-41)$ & $23(20-34)$ & NS \\
\hline Diabetes [n (\%)] & $3(10 \%)$ & $2(10 \%)$ & $1(11 \%)$ & NS \\
\hline Hypertension [n (\%)] & $14(48 \%)$ & $12(60 \%)$ & $2(22 \%)$ & 0.02 \\
\hline CHD [n (\%)] & $1(3 \%)$ & $0(0 \%)$ & $1(11 \%)$ & NS \\
\hline Pulmonary disease [n (\%)] & $10(34 \%)$ & $7(35 \%)$ & $3(33 \%)$ & NS \\
\hline Renal disease [n (\%)] & $17(59 \%)$ & $16(80 \%)$ & $1(11 \%)$ & 0.002 \\
\hline Postoperative mortality [n (\%)] & $2(7 \%)$ & $2(10 \%)$ & $0(0 \%)$ & NS \\
\hline Disease-free survival [months, median (range) $]^{+}$ & $14(2-170)$ & $14(2-150)$ & $22(4-170)$ & NS \\
\hline $\begin{array}{l}\text { Time from primary tumor to metastasis [months, } \\
\text { median (range)] }\end{array}$ & $89(6-331)$ & $116(6-331)$ & $66(13-108)$ & 0.07 \\
\hline Metachronous diagnosis [n (\%)] & $28(97 \%)$ & $20(100 \%)$ & $8(89 \%)$ & NS \\
\hline 5-year survival rate $[\mathrm{n}(\%)]^{*}$ & $22(82 \%)$ & $16(89 \%)$ & $6(67 \%)$ & NS \\
\hline Overall survival rate $[\mathrm{n}(\%)]^{*}$ & $19(70 \%)$ & $14(78 \%)$ & $5(56 \%)$ & NS \\
\hline
\end{tabular}

$C H D$ coronary heart disease, $y$ years, $m R C C$ Metastatic renal cell carcinoma, $m n R C C$ Metastatic other tumor entities

${ }^{+}$Five patients without R0-Resection excluded *Two postoperatively-deceased RCC patients excluded 
Table 2 Tumor-specific and diagnostic data

\begin{tabular}{|c|c|c|c|c|}
\hline Parameter & All $(n=29)$ & $\operatorname{mRCC}(\mathrm{n}=20)$ & $\operatorname{mnRCC}(n=9)$ & $\mathrm{p}$ \\
\hline Localization of tumor $[\mathrm{n}(\%)]$ & & & & NS \\
\hline Head & $6(21 \%)$ & $3(15 \%)$ & $3(33 \%)$ & \\
\hline Body & $6(21 \%)$ & $3(15 \%)$ & $3(33 \%)$ & \\
\hline Tail & $8(28 \%)$ & $5(25 \%)$ & $3(33 \%)$ & \\
\hline More than one localization & $9(31 \%)$ & $9(45 \%)$ & $0(0 \%)$ & \\
\hline Advance of disease [n (\%)] & & & & NS \\
\hline Single metastasis & $17(59 \%)$ & $8(40 \%)$ & $9(100 \%)$ & \\
\hline Further pancreatic metastasis & $12(41 \%)$ & $12(60 \%)$ & $0(0 \%)$ & \\
\hline Extra-pancreatic metastasis & $13(45 \%)$ & $8(40 \%)$ & $5(56 \%)$ & \\
\hline Past extra-pancreatic metastasis & $19(65 \%)$ & $12(60 \%)$ & $7(78 \%)$ & \\
\hline Tumor size [mm, median (range)] & $21(4-60)$ & $19(4-50)$ & $32(18-60)$ & NS \\
\hline Initial tumor stage & & & & NS \\
\hline $\mathrm{T} 1$ & $8(27 \%)$ & $7(35 \%)$ & $1(11 \%)$ & \\
\hline $\mathrm{T} 2$ & $4(14 \%)$ & $3(15 \%)$ & $1(11 \%)$ & \\
\hline $\mathrm{T} 3$ & $6(21 \%)$ & $3(15 \%)$ & $3(33 \%)$ & \\
\hline $\mathrm{TX}$ & $11(38 \%)$ & $7(35 \%)$ & $4(45 \%)$ & \\
\hline Initial lymph node stage & & & & NS \\
\hline No & $15(52 \%)$ & $11(55 \%)$ & $4(44 \%)$ & \\
\hline $\mathrm{N} 1$ & $1(3 \%)$ & $0(0 \%)$ & $1(12 \%)$ & \\
\hline NX & $13(45 \%)$ & $9(45 \%)$ & $4(44 \%)$ & \\
\hline Symptoms [n (\%)] & & & & NS \\
\hline Pain & $2(7 \%)$ & $1(5 \%)$ & $1(11 \%)$ & \\
\hline Jaundice & $1(3 \%)$ & $1(5 \%)$ & $0(0 \%)$ & \\
\hline Diagnostic method [n (\%)] & & & & 0.014 \\
\hline CT & $18(62 \%)$ & $15(75 \%)$ & $3(33 \%)$ & \\
\hline MRI & $13(45 \%)$ & $10(50 \%)$ & $3(33 \%)$ & \\
\hline $\mathrm{CT}$ and MRI & $6(21 \%)$ & $5(25 \%)$ & $1(11 \%)$ & \\
\hline PET-CT & $14(48 \%)$ & $8(40 \%)$ & $6(67 \%)$ & \\
\hline Diagnostic sensitivity & & & & $\mathrm{n} / \mathrm{a}$ \\
\hline CT & $89 \%$ & $93 \%$ & $67 \%$ & \\
\hline MRI & $92 \%$ & $90 \%$ & $100 \%$ & \\
\hline PET-CT & $71 \%$ & $50 \%$ & $100 \%$ & \\
\hline
\end{tabular}

$m R C C$ Metastatic renal cell carcinoma, $m n R C C$ Metastatic other tumor entities hospital (Table 3). All postoperatively deceased $(n=2,7 \%)$ were patients with mRCC.

13 patients with extra-pancreatic metastasis underwent further therapy. In 7 patients (54\%) extra-pancreatic metastasis were resected concurrently with pancreatic resection. Five patients $(38 \%)$ received resection at a later time, 2 patients $(15 \%)$ had radiation and 1 patient $(8 \%)$ with cerebral metastasis underwent LINAC based radiosurgery (Table 4). 18 patients (12 mRCC and $6 \mathrm{nmRCC}$ ) underwent further oncological therapies. Follow-up was not available in two patients. All data are presented in Table 4.

Interestingly, the disease-free survival appears to be shorter in patients with mRCC than in patients without (14 vs. 22 months, $\mathrm{p}=0.399$, Fig. 1). 5-year survival was $89 \%$ for $\mathrm{mRCC}$ (excluding two patients who died postoperatively) and $67 \%$ for mnRCC $(p=0.229)$. Overall survival was $78 \%$ and $57 \%$ for $\mathrm{mRCC}$ and $\mathrm{mnRCC}$, respectively $(\mathrm{p}=0.130$, Fig. 2). Median survival for mRCC was 54 months (range 11-150), 43 months (range 18-171) for colon and ovarian carcinoma and 28 months (range 8-62) for melanoma.

\section{Subgroup analysis}

Median overall survival was 63.8 (range 15-171) months $(n=18)$ and 28.4 (range 9-103) months $(n=9)$ for patients with and without history of previous metastases $(p=0.878)$, respectively.

Median overall survival was 41.8 (range 8-171) months $(n=14)$ and 55.7 (range 25-150) months $(n=13)$ for patients with single and with multiple metastases $(p=0.202)$, respectively. 
Table 3 Operative data and postoperative complications

\begin{tabular}{|c|c|c|c|c|}
\hline Parameter & All $(n=29)$ & $\operatorname{mRCC}(\mathrm{n}=20)$ & $\operatorname{mnRCC}(\mathrm{n}=9)$ & $\mathrm{p}$ \\
\hline Surgical approach [n (\%)] & & & & NS \\
\hline Pancreatic head resection & $6(21 \%)$ & $3(15 \%)$ & $3(33 \%)$ & \\
\hline Distal pancreatectomy & $17(59 \%)$ & $11(55 \%)$ & $6(67 \%)$ & \\
\hline Pancreatectomy & $6(21 \%)$ & $6(30 \%)$ & $0(0 \%)$ & \\
\hline Resection [n (\%)] & & & & NS \\
\hline R0 & $25(87 \%)$ & $17(85 \%)$ & $8(89 \%)$ & \\
\hline $\mathrm{R} 1$ & $3(10 \%)$ & $3(15 \%)$ & $0(0 \%)$ & \\
\hline $\mathrm{R} 2$ & $0(0 \%)$ & $0(0 \%)$ & $0(0 \%)$ & \\
\hline $\mathrm{Rx}$ & $1(3 \%)$ & $0(0 \%)$ & $1(11 \%)$ & \\
\hline Perioperative blood transfusion [n (\%)] & $4(14 \%)$ & $4(20 \%)$ & 0 & NS \\
\hline Operative time [min, median (range)] & $281(154-556)$ & $287(154-556)$ & $266(172-527)$ & NS \\
\hline ICU stay [days, median (range)] & $4(1-45)$ & $5(2-35)$ & $3(1-45)$ & NS \\
\hline Hospital stay [days, median (range)] & $18(8-99)$ & 19(11-699) & $13(8-28)$ & NS \\
\hline \multicolumn{5}{|l|}{ Postoperative complications*[n (\%)] } \\
\hline Overall & $21(72 \%)$ & $14(70 \%)$ & $7(78 \%)$ & NS \\
\hline 2 & $12(52 \%)$ & $8(40 \%)$ & $4(45 \%)$ & \\
\hline 3 & $5(17 \%)$ & $2(10 \%)$ & $3(33 \%)$ & \\
\hline 4 & $2(7 \%)$ & $2(10 \%)$ & $0(0 \%)$ & \\
\hline 5 & $2(7 \%)$ & $2(10 \%)$ & $0(0 \%)$ & \\
\hline $\operatorname{POPF}[\mathrm{n}(\%)]^{+}$ & & & & NS \\
\hline BL & $3(13 \%)$ & $2(14 \%)$ & $1(11 \%)$ & \\
\hline B & $11(48 \%)$ & $7(50 \%)$ & $4(44 \%)$ & \\
\hline $\mathrm{C}$ & $3(13 \%)$ & $2(14 \%)$ & $1(11 \%)$ & \\
\hline \multicolumn{5}{|l|}{ DGE $[\mathrm{n}(\%)]$} \\
\hline A & $5(17 \%)$ & $3(15 \%)$ & $2(22 \%)$ & NS \\
\hline B & $3(10 \%)$ & $3(15 \%)$ & $0(0 \%)$ & \\
\hline $\mathrm{PPH}[\mathrm{n}(\%)]$ & $4(14 \%)$ & $2(10 \%)$ & $2(22 \%)$ & NS \\
\hline Relaparotomy [n (\%)] & $5(17 \%)$ & $4(20 \%)$ & $1(11 \%)$ & NS \\
\hline Intervention [n (\%)] & $8(28 \%)$ & $6(30 \%)$ & $2(22 \%)$ & NS \\
\hline
\end{tabular}

According to Clavien-Dindo-classification [16, 17]

$B L$ biochemical leakage, $D G E$ delayed gastric emptying, $I C U$ intensive care unit, $m R C C$ Metastatic renal cell carcinoma, $m n R C C$ Metastatic other tumor entities, $P O P F$ postoperative pancreatic fistula, $P P H$ postpancreatectomy hemorrhage

${ }^{+}$Rates exclude pancreatectomy
Median overall survival was 41.8 (range 8-171) months $(\mathrm{n}=17)$ and 51 (range 11-150) months $(\mathrm{n}=10)$ for patients with single pancreatic and with multiple pancreatic metastases $(p=0.289)$, respectively.

\section{Discussion}

Patients with secondary metastatic pancreatic malignancy are rare, usually show widespread disease or the primary tumor has aggressive tumor biology with poor prognosis. Due to advanced disease, therapy of pancreatic metastasis appears to be limited, but recent publications show evidence of survival benefit for patients after metastasectomy. Specific symptoms of pancreatic metastasis are mostly lacking, and diagnosis is often made as part of follow-up care. The symptom rate of our patients was only $34 \%$ and only two of our patients showed tumor-related symptoms. Reddy et al. reported an unusually high symptom rate of more than $90 \%$, but most were unspecific such as abdominal pain [18]. The rate reported by Reddy et al. might be attributable to data age, since follow-up care was not yet standardized at that time, leading to a diagnosis of metastatic lesions only in case of symptoms. Other studies indicated symptom rates of approximately $20-60 \%$ [3, 9, 10, 19, 20]. Most common symptoms are abdominal pain and weight loss, followed by more specific symptoms such as nausea and vomiting, gastrointestinal bleeding and jaundice. Sperti et al. reported a relief of symptoms after metastasectomy until disease recurrence [1]. Surgical treatment for metastatic diseases 


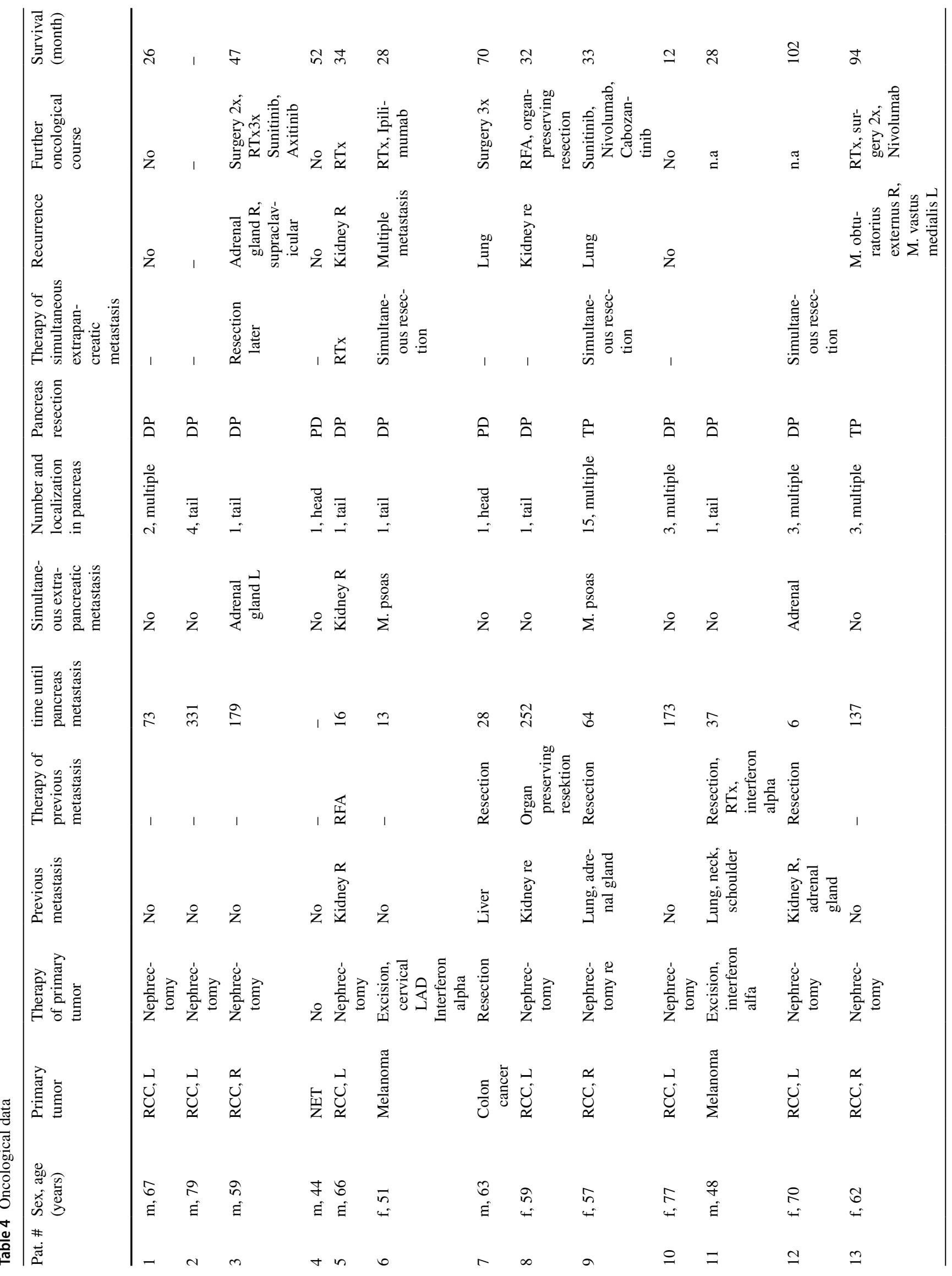




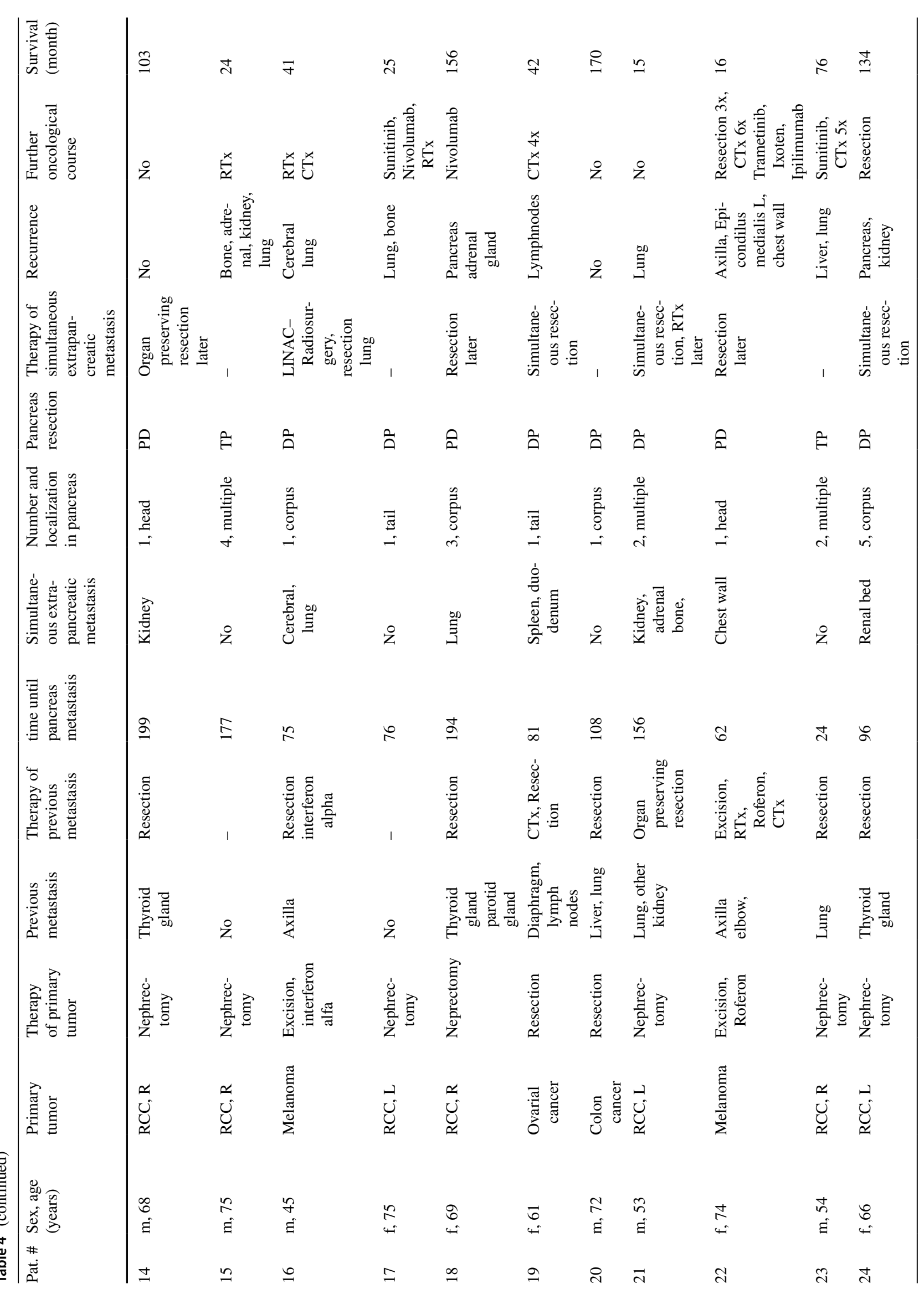




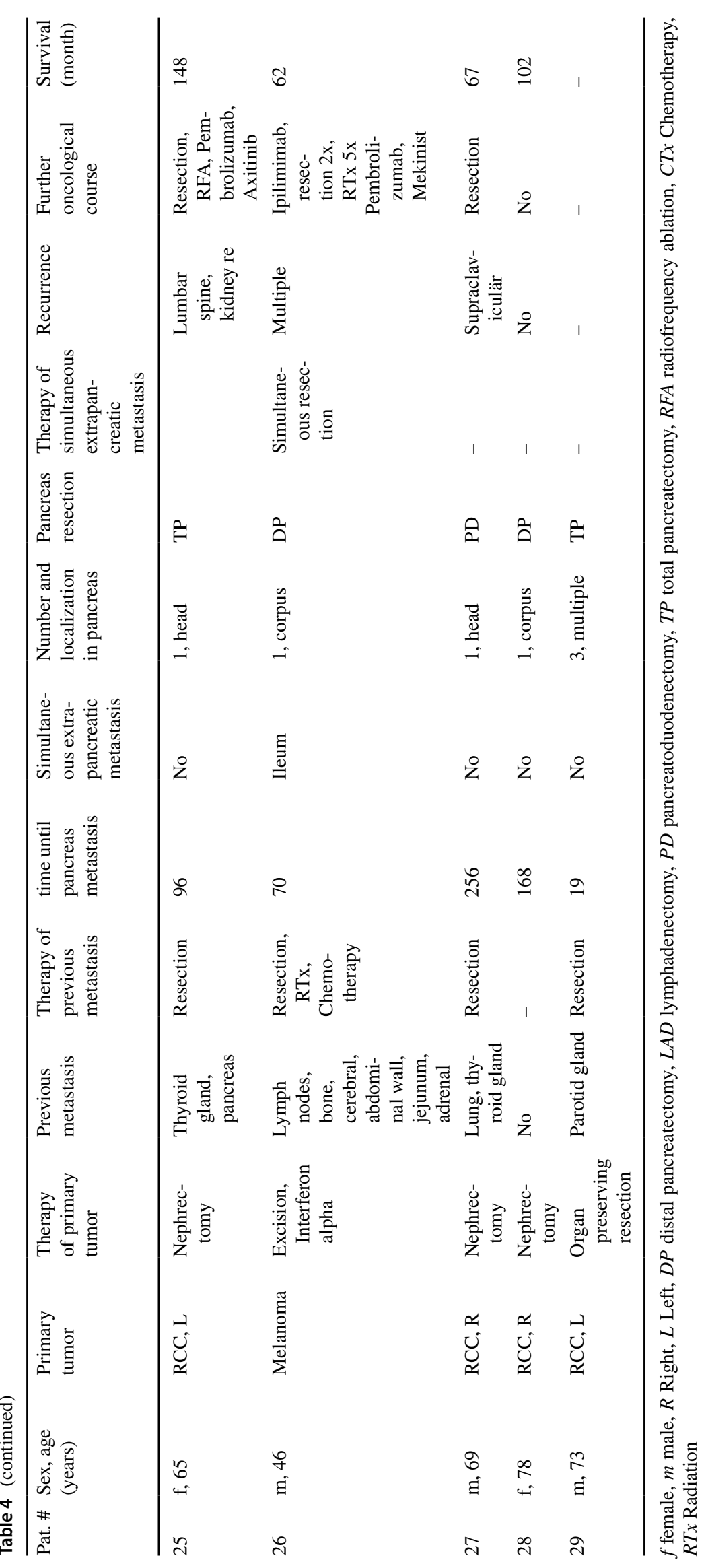




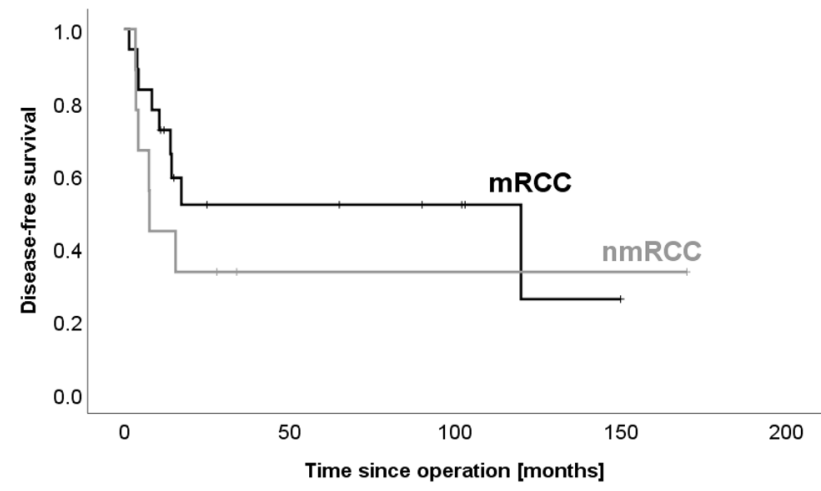

Fig. 1 Patients with metastatic renal cell carcinoma (mRCC) might have a shorter disease-free survival than patients with pancreatic metastasis due to other tumor entities (nmRCC) (14 vs. 22 months, $\mathrm{p}=0.399)$

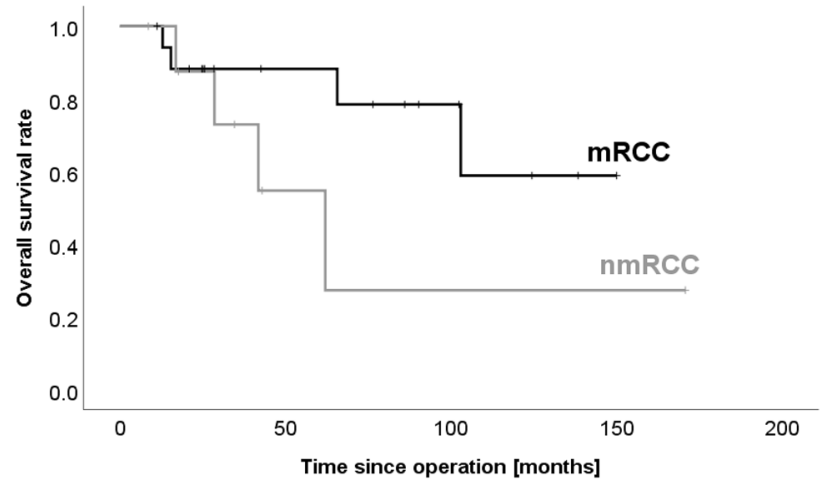

Fig. 2 Patients with metastatic renal cell carcinoma (mRCC) might have a better overall survival rate than patients with pancreatic metastasis due to other tumor entities (nmRCC) (78 vs. $56 \%, \mathrm{p}=0.130)$

of liver and lung is well-established, but treatment of metastatic disease of other organs such as the pancreas is still under discussion [21]. The morbidity rate of pancreas surgery is still high, as pancreatic fistula occurs in approximately $20-30 \%$ of patients [22, 23]. Severe postoperative complications are diagnosed in $20 \%$ of patients [24] and the overall morbidity rate remains up to $60 \%$ [25]. The morbidity rate of our cohort was even higher, which might be attributable to a small sample-size, patient' selection and thorough documentation of complications. The high rate of pancreatic fistula in our cohort might be attributable to the texture of the pancreas and drain management with drains in place over 21 days. It is known that the occurrence of pancreatic fistula depends on the texture of pancreas and that soft texture, which is expected in our cohort to be different than in pancreatic ductal adenocarcinoma, is associated with an increased POPF rate [26]. Furthermore, most of our patients received distal pancreatectomy, which is also known to be associated with a higher POPF rate [27]. These are also confirmed by our results, as we found a lower rate of POPF (B and C) rate in our patents, which underwent pancreatic resection due to pancreatic ductal adenocarcinoma. POPF $\mathrm{B}$ and $\mathrm{C}$ Rate was here $9 \%$ in patients after pancreatoduodenectomy and $20 \%$ in patients after distal pancreatectomy. In addition, a smaller pancreatic duct diameter is associated with an increased risk of POPF [28], which is to expect in patients with pancreatic metastasis unlike pancreatic ductal adenocarcinoma.

Once surgical complications have been overcome, survival rate appears to be significantly higher in resected patients [20, 29]. Results of our analysis present the justifiable possibility of curative-intended pancreas surgery in selected patients confirming data previously published by others. Our data are not able to prove superiority of surgery over other therapies as we have no comparable data about a non-surgically-treated group. However, despite advanced tumor disease $70 \%$ of our patients were alive at the end of follow-up, which is approximately ten times higher than the 5-year survival rate of patients with pancreatic ductal adenocarcinoma [30]. Selection criteria for our patients who were eligible for surgery of pancreatic metastasis, were fully resectable pancreatic metastasis and an overall low-to-medium surgical risk assessed by a combination of pre-existing illnesses and the current condition. The kind and frequency of pretreatment and the previously-diagnosed tumor entity was not crucial for decision. The most frequently diagnosed tumor origin was $\mathrm{mRCC}$ in our cohort. mRCC is known to be the most common primary tumor for pancreatic metastasis $[8,11,12]$. Recent publications have indicated a survival benefit for patients with metastatic pancreatic malignancy from renal cell cancer compared to other primary cancers $[1,11,31,32]$. Our results confirm this. Even if patients with $\mathrm{mRCC}$ had a slightly higher ASA Score and more pre-existing illnesses, the 5-year survival of these patients was higher compared to patients with mnRCC (89 vs. $67 \%$ ). Interestingly, the disease-free survival was shorter in patients with mRCC compared to mnRCC patients, as was also reported by others $[8,33]$. The influence of different tumor pathological types on survival is well-known. The 5-year survival rate for malignancies from melanoma, sarcoma, breast cancer, and colorectal cancer is $20 \%, 32 \%$, $34 \%$, and $42 \%$, respectively $[8,34]$. The survival rate of our mnRCC patients is nearly twice as high as the other reported rates. The observed rate of nearly $90 \%$ in mRCC patients is also impressively high, given that the expected 5 -year survival for extended disease is less than 20\% [35]. These observations are not only attributable to patient selection, but also to the advantage of improved follow-up care leading to a symptom-free, earlier diagnosis, as it is known that symptomatic pancreatic metastasis is associated with decreased survival [33]. In addition, new targeted therapies after surgery are able to significantly improve overall 
survival of patients [36]. Furthermore, the impressively high survival of advanced-stage cancer patients, the rareness and latency of pancreatic metastasis speak for an underlying exceptional tumor biology. Confirming these hypotheses, most of the patients had a more than 5-year disease-free interval between primary diagnosis and diagnosis of pancreatic lesions, which is also supported by others' data [37, 38]. Late recurrence of RCC has been known for decades [39], but the pancreas might be a special localization for recurrent cancer disease not only of RCC. In our cohort, the time from primary diagnosis to metastasis was nearly twice as long in mRCC patients compared to nmRCC patients. Furthermore, multiple metastasis of pancreas was only found in $\mathrm{mRCC}$ patients, which has also been reported by others $[8,33]$. Thus, the origin of metastases could not only determine prognosis but also the intraoperative extent of resection. The prognosis of patients with advanced disease might be also influenced by pancreatic metastasis: Diagnosis of pancreatic metastasis had a positive impact on survival of patients treated with molecular targeted therapies [34, 37, $38,40]$. Molecular targeted therapies such as sunitinib are associated with side-effect rates up to $50 \%$, and early disruption of therapy might worsen the outcome of treated patients with mRCC [41, 42]. Motzer et al. reported a progressionfree survival of mRCC patients with sunitinib of 11 months, which is slightly lower than the observed disease-free survival of 14 months in our patients after pancreatic surgery [43]. Another study indicated an even lower survival of less than 6 months [44]. But it must be taken into account that both studies observed all patients with mRCC, not only those with pancreatic metastases. In our cohort, the disease-free survival of 4 patients with pancreatic and extra-pancreatic metastases was only 6 months, but the impact of the result is limited and should lead to further research into whether surgical or non-surgical treatment is the more promising approach for advanced mRCC. Grassi et al. reported that local treatment of pancreatic metastasis, mostly surgery, might be more promising than targeted therapy in $\mathrm{mRCC}$ patients [38]. For tumor entities other than RCC, it remains also largely unclear whether surgical or non-surgical therapy is the more promising approach. Ollila et al. observed that median survival in patients undergoing curative resection due to gastrointestinal melanoma metastasis was significantly better than in those undergoing palliative procedures and nonsurgical interventions ( 49 vs. 5 and 6 months, respectively) [45]. Nevertheless, eligibility for pancreas resection has to be critically evaluated, as pancreas surgery has high morbidity rates and life-threatening complications [25].

Retrospective analyses are limited by lack of documentation and documentation errors. Due to the rareness of pancreatic metastasis, sample-size of our cohort study is really small making it hard to deliver valid results. We were able to obtain data of 29 patients, which is a bigger number than other monocentric analyses have provided. However, the cohort of patients is inhomogeneous due to different tumor entities and different pre-treatments, which makes it hard to compare patient data. Subgroup analysis is also not a promising approach for data comparison, as subgroups are even smaller. Research about rare entities is always limited due to small cohorts, nevertheless, our results are interesting and show tendencies on which to base further research. We were not able to provide data of molecular markers as they were not measured in most of our patients, but we will put more emphasis on these in future research. Due to the scientific advances of the last decade, further research must focus on molecular markers of patients with pancreatic metastasis to identify patients who will benefit from pancreas surgery.

\section{Conclusion}

Pancreas resections appear to be successful in treating patients with advanced cancer with pancreatic metastases. Survival is associated with the histology of primary tumor. Further research is necessary to compare surgical and non-surgical approaches. Focus should be placed on molecular markers to elucidate the mechanisms of pancreatic metastasis in order to choose the therapeutic approach suitable for the individual patient.

Acknowledgements Open Access funding provided by Projekt DEAL.

Author contributions SC, SFF and UAW are responsible for conception and design. Data was collected by OS, JH, CK and SC. Data was analyzed by AKL, OS and JH. AKL wrote the manuscript with help of SC. SFF, CK and UAW revised the article.

Funding No funding was received.

Data availability The datasets used and analyzed during the current study are available from the corresponding author on reasonable request.

\section{Compliance with ethical standards}

Conflict of interest The authors have no conflicts of interest or financial ties to disclose.

Ethics approval Study was approved by the local Ethics Committee. Due to the retrospective study design and the anonymization of data, consent to participate was not necessary. An identification of the participants by a third party is not possible.

Informed consent Not applicable.

Open Access This article is licensed under a Creative Commons Attribution 4.0 International License, which permits use, sharing, adaptation, distribution and reproduction in any medium or format, as long as you give appropriate credit to the original author(s) and the source, provide a link to the Creative Commons licence, and indicate if changes 
were made. The images or other third party material in this article are included in the article's Creative Commons licence, unless indicated otherwise in a credit line to the material. If material is not included in the article's Creative Commons licence and your intended use is not permitted by statutory regulation or exceeds the permitted use, you will need to obtain permission directly from the copyright holder. To view a copy of this licence, visit http://creativecommons.org/licenses/by/4.0/.

\section{References}

1. Sperti C, Moletta L, Patanè G (2014) Metastatic tumors to the pancreas: the role of surgery. World J Gastrointest Oncol 6:381-392. https://doi.org/10.4251/wjgo.v6.i10.381

2. Sperti C, Pasquali C, Liessi G et al (2003) Pancreatic resection for metastatic tumors to the pancreas. J Surg Oncol 83:161-166. https://doi.org/10.1002/jso.10262

3. Niess H, Conrad C, Kleespies A et al (2013) Surgery for metastasis to the pancreas: is it safe and effective? J Surg Oncol 107:859-864. https://doi.org/10.1002/jso.23333

4. Stankard CE, Karl RC (1992) The treatment of isolated pancreatic metastases from renal cell carcinoma: a surgical review. Am J Gastroenterol 87:1658-1660

5. Nakamura E, Shimizu M, Itoh T, Manabe T (2001) Secondary tumors of the pancreas: clinicopathological study of 103 autopsy cases of Japanese patients. Pathol Int 51:686-690

6. Strobel O, Buechler MW (2015) Pancreatic metastases from tumors in the urogenital tract. Gastrointest Tumors 2:75-82. https://doi.org/10.1159/000431045

7. Strobel O, Hackert T, Hartwig W et al (2009) Survival data justifies resection for pancreatic metastases. Ann Surg Oncol 16:3340-3349. https://doi.org/10.1245/s10434-009-0682-3

8. Masetti M, Zanini N, Martuzzi F et al (2010) Analysis of prognostic factors in metastatic tumors of the pancreas: a singlecenter experience and review of the literature. Pancreas 39:135143. https://doi.org/10.1097/MPA.0b013e3181bae9b3

9. Tosoian JJ, Cameron JL, Allaf ME et al (2014) Resection of isolated renal cell carcinoma metastases of the pancreas: outcomes from the Johns Hopkins Hospital. J Gastrointest Surg 18:542-548. https://doi.org/10.1007/s11605-013-2278-2

10. Sellner F, Tykalsky N, De Santis M et al (2006) Solitary and multiple isolated metastases of clear cell renal carcinoma to the pancreas: an indication for pancreatic surgery. Ann Surg Oncol 13:75-85. https://doi.org/10.1245/ASO.2006.03.064

11. Adler H, Redmond CE, Heneghan HM et al (2014) Pancreatectomy for metastatic disease: a systematic review. Eur J Surg Oncol 40:379-386. https://doi.org/10.1016/j.ejso.2013.12.022

12. Sperti C, Pozza G, Brazzale AR et al (2016) Metastatic tumors to the pancreas: a systematic review and meta-analysis. Minerva Chir 71:337-344

13. Bassi C, Marchegiani G, Dervenis C et al (2017) The 2016 update of the International Study Group (ISGPS) definition and grading of postoperative pancreatic fistula: 11 Years After. Surgery 161:584-591. https://doi.org/10.1016/j.surg.2016.11.014

14. Wente MN, Veit JA, Bassi C et al (2007) Postpancreatectomy hemorrhage $(\mathrm{PPH})$ : an international study group of pancreatic surgery (ISGPS) definition. Surgery 142:20-25. https://doi. org/10.1016/j.surg.2007.02.001

15. Wente MN, Bassi C, Dervenis C et al (2007) Delayed gastric emptying (DGE) after pancreatic surgery: a suggested definition by the International Study Group of Pancreatic Surgery (ISGPS). Surgery 142:761-768. https://doi.org/10.1016/j. surg.2007.05.005
16. Dindo D, Demartines N, Clavien P-A (2004) Classification of surgical complications. Ann Surg 240:205-213. https://doi. org/10.1097/01.sla.0000133083.54934.ae

17. Clavien PA, Barkun J, de Oliveira ML et al (2009) The Clavien-Dindo classification of surgical complications: five-year experience. Ann Surg 250:187-196. https://doi.org/10.1097/ SLA.0b013e3181b13ca2

18. Reddy S, Edil BH, Cameron JL et al (2008) Pancreatic resection of isolated metastases from nonpancreatic primary cancers. Ann Surg Oncol 15:3199-3206. https://doi.org/10.1245/s1043 4-008-0140-7

19. Dong J, Cong L, Zhang T-P, Zhao Y-P (2016) Pancreatic metastasis of renal cell carcinoma. Hepatobiliary Pancreat Dis Int 15:30-38. https://doi.org/10.1016/S1499-3872(16)60052-8

20. Zerbi A, Ortolano E, Balzano G et al (2008) Pancreatic metastasis from renal cell carcinoma: which patients benefit from surgical resection? Ann Surg Oncol 15:1161-1168. https://doi. org/10.1245/s10434-007-9782-0

21. Untch BR, Allen PJ (2014) Pancreatic metastasectomy: the memorial sloan-kettering experience and a review of the literature. J Surg Oncol 109:28-30. https://doi.org/10.1002/jso.23460

22. Pedrazzoli S (2017) Pancreatoduodenectomy (PD) and postoperative pancreatic fistula (POPF). Medicine (Baltimore) 96:e6858. https://doi.org/10.1097/MD.0000000000006858

23. Bassi C, Dervenis C, Butturini G et al (2005) Postoperative pancreatic fistula: an international study group (ISGPF) definition. Surgery 138:8-13. https://doi.org/10.1016/j.surg.2005.05.001

24. Wellner UF, Keck T (2017) Quality indicators in pancreatic surgery: lessons learned from the German DGAV StuDoQlpancreas registry. Visc Med 33:126-130. https://doi.org/10.1159/00045 6045

25. Ho C, Kleeff J, Friess H, Büchler MW (2005) Complications of pancreatic surgery. HPB 7:99-108. https://doi. org/10.1080/13651820510028936

26. Peng Y-P, Zhu X-L, Yin L-D et al (2017) Risk factors of postoperative pancreatic fistula in patients after distal pancreatectomy: a systematic review and meta-analysis. Sci Rep 7:185. https:// doi.org/10.1038/s41598-017-00311-8

27. McMillan MT, Christein JD, Callery MP et al (2016) Comparing the burden of pancreatic fistulas after pancreatoduodenectomy and distal pancreatectomy. Surgery 159:1013-1022. https ://doi.org/10.1016/j.surg.2015.10.028

28. Hu B-Y, Wan T, Zhang W-Z, Dong J-H (2016) Risk factors for postoperative pancreatic fistula: analysis of 539 successive cases of pancreaticoduodenectomy. World J Gastroenterol 22:7797. https://doi.org/10.3748/wjg.v22.i34.7797

29. Mousa OY, Shah R, Hajar N, Landas SK (2015) Periampullary and pancreatic metastases of renal cell carcinoma: an underdiagnosed event. World J Oncol 6:378-380. https://doi. org/10.14740/wjon911w

30. Hirshberg Foundation For Pancreatic Cancer Research (2019) Prognosis. https://pancreatic.org/pancreatic-cancer/about-thepancreas/prognosis/. Accessed 16 Jul 2019

31. Schwarz L, Sauvanet A, Regenet N et al (2014) Long-term survival after pancreatic resection for renal cell carcinoma metastasis. Ann Surg Oncol 21:4007-4013. https://doi.org/10.1245/ s10434-014-3821-4

32. Konstantinidis IT, Dursun A, Zheng H et al (2010) Metastatic tumors in the pancreas in the modern era. J Am Coll Surg 211:749-753. https://doi.org/10.1016/j.jamcollsur g.2010.08.017

33. Chua TC, Petrushnko W, Mittal A et al (2016) Pancreatic metastasectomy - an analysis of survival outcomes and prognostic factors. J Gastrointest Surg 20:1188-1193. https://doi.org/10.1007/ s11605-016-3106-2 
34. Deutsch GB, Flaherty DC, Kirchoff DD et al (2017) Association of surgical treatment, systemic therapy, and survival in patients with abdominal visceral melanoma metastases, 1965-2014: relevance of surgical cure in the era of modern systemic therapy. JAMA Surg 152:672-678. https://doi.org/10.1001/jamasurg.2017.0459

35. Lane BR, Kattan MW (2008) Prognostic models and algorithms in renal cell carcinoma. Urol Clin North Am 35:613-625. https:// doi.org/10.1016/j.ucl.2008.07.003

36. Bai X, Fisher DE, Flaherty KT (2019) Cell-state dynamics and therapeutic resistance in melanoma from the perspective of MITF and IFN $\gamma$ pathways. Nat Rev Clin Oncol. https://doi.org/10.1038/ s41571-019-0204-6

37. Shimizu Y, Iguchi T, Tamada S et al (2018) Oncological outcomes classified according to metastatic lesions in the era of molecular targeted drugs for metastatic renal cancer. Mol Clin Oncol. https ://doi.org/10.3892/mco.2018.1614

38. Grassi P, Doucet L, Giglione P et al (2016) Clinical impact of pancreatic metastases from renal cell carcinoma: a multicenter retrospective analysis. PLoS ONE 11:e0151662. https://doi. org/10.1371/journal.pone.0151662

39. McNichols DW, Segura JW, DeWeerd JH (1981) Renal cell carcinoma: long-term survival and late recurrence. J Urol 126:17-23. https://doi.org/10.1016/S0022-5347(17)54359-1

40. Grassi P, Verzoni E, Mariani L et al (2013) Prognostic role of pancreatic metastases from renal cell carcinoma: results from an italian center. Clin Genitourin Cancer 11:484-488. https://doi. org/10.1016/j.clgc.2013.04.022

41. Dreicer R (2009) Management of side effects associated with sunitinib therapy for patients with renal cell carcinoma. Onco Targets Ther. https://doi.org/10.2147/OTT.S4052

42. Ishiyama R, Ishihara H, Kondo T et al (2019) Negative effect of immediate sunitinib interruption on survival in patients with metastatic renal cell carcinoma. Vivo (Brooklyn) 33:2153-2160. https://doi.org/10.21873/invivo.11717

43. Motzer RJ, Hutson TE, Tomczak P et al (2007) Sunitinib versus interferon alfa in metastatic renal-cell carcinoma. N Engl J Med 356:115-124. https://doi.org/10.1056/NEJMoa065044

44. Ghosn M, Eid R, Hamada E et al (2019) OSSMAR: an observational study to describe the use of sunitinib in real-life practice for the treatment of metastatic renal cell carcinoma. J Glob Oncol. https://doi.org/10.1200/JGO.18.00238

45. Ollila DW, Essner R, Wanek LA, Morton DL (1996) Surgical resection for melanoma metastatic to the gastrointestinal tract. Arch Surg 131(975-9):979-980

Publisher's Note Springer Nature remains neutral with regard to jurisdictional claims in published maps and institutional affiliations. 